\title{
$\mathrm{ZnO}$ 박막 성장을 위한 $\mathrm{Zn}$ 전구체와 $\mathrm{Si}(001)$ 표면과의 초기 반응
}

\author{
김대희 · 이가원* 김영철 ${ }^{\dagger}$ \\ 한국기술교육대학교 신소재공학과, *충남대학교 전자공학과
}

\section{Initial Reaction of Zn Precursors with Si (001) Surface for $\mathrm{ZnO}$ Thin-Film Growth}

\author{
Dae-Hee Kim, Ga-Won Lee* and Yeong-Cheol Kim ${ }^{\dagger}$ \\ Department of Materials Engineering, Korea University of Technology and Education, Cheonan, 330-708, Korea \\ *Department of Electronics Engineering, Chungnam National University, Daejeon, 305-764, Korea
}

(2010년 7월 23일 접수 : 2010년 8월 21일 최종수정 : 2010년 8월 21일 채택)

\begin{abstract}
We studied the initial reaction mechanism of $\mathrm{Zn}$ precursors, namely, di-methylzinc $\left(\mathrm{Zn}\left(\mathrm{CH}_{3}\right)_{2}, \mathrm{DMZ}\right)$ and $d i$ ethylzinc $\left(\mathrm{Zn}\left(\mathrm{C}_{2} \mathrm{H}_{5}\right)_{2}, \mathrm{DEZ}\right)$, for zinc oxide thin-film growth on a $\mathrm{Si}(001)$ surface using density functional theory. We calculated the migration and reaction energy barriers for DMZ and DEZ on a fully hydroxylized Si (001) surface. The Zn atom of DMZ or DEZ was adsorbed on an $\mathrm{O}$ atom of a hydroxyl $(-\mathrm{OH})$ due to the lone pair electrons of the $\mathrm{O}$ atom on the Si (001) surface. The adsorbed DMZ or DEZ migrated to all available surface sites, and rotated on the $\mathrm{O}$ atom with low energy barriers in the range of $0.00-0.13 \mathrm{eV}$. We considered the DMZ or DEZ reaction at all available surface sites. The rotated and migrated DMZs reacted with the nearest $-\mathrm{OH}$ to produce a uni-methylzinc $\left(-\mathrm{ZnCH}_{3}, \mathrm{UMZ}\right)$ group and methane $\left(\mathrm{CH}_{4}\right)$ with energy barriers in the range of $0.53-0.78 \mathrm{eV}$. In the case of the DEZs, smaller energy barriers in the range of $0.21-0.35 \mathrm{eV}$ were needed for its reaction to produce a uni-ethylzinc $\left(-\mathrm{ZnC}_{2} \mathrm{H}_{5}, \mathrm{UEZ}\right)$ group and ethane $\left(\mathrm{C}_{2} \mathrm{H}_{6}\right)$. Therefore, DEZ is preferred to DMZ due to its lower energy barrier for the surface reaction.
\end{abstract}

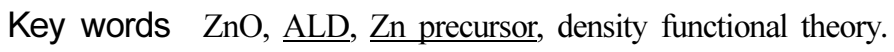

\section{1. 서}

대표적인 투명 전도 산화물(transparent conducting oxide, $\mathrm{TCO})$ 인 산화 아연 $(\mathrm{ZnO})$ 은 상온에서 $3.37 \mathrm{eV}$ 의 넓은 밴 드갭 (band-gap)과 $60 \mathrm{meV}$ 의 큰 엑시톤 결합 에너지 (exciton binding energy)를 갖는 II-VI 족 화합물이다. ${ }^{1)}$ 이 런 장점을 이용하여 $\mathrm{ZnO}$ 는 가스 센서(gas sensor), 변환 기(transducer), 히터(heater), 서리 제거 장치(defroster), 태 양 전지(solar cell), 희석된 자기 반도체(diluted magnetic semiconductor), 전자 소자(electronic device), 광전자 소자 (optoelectronic device), 발광 다이오드(light emitting diode, LED), 표면 음파 소자(surface acoustic wave device, SAW), 투명 전극(transparent electrode)으로의 다양한 응 용을 갖는 물질이다. ${ }^{2-9)}$ 최근에는 저온 성장, 높은 전계 효 과 이동도(field effect mobility, $0.2-40 \mathrm{~cm}^{2} / \mathrm{Ns}$ ), 우수한 on-off 비율 $\left(10^{3}-10^{6}\right)$, 높은 가시광 파장 투명도 등이 요구

\footnotetext{
${ }^{\dagger}$ Corresponding author

E-Mail : ckim@kut.ac.kr (Y. -C. Kim)
}

되는 투명 박막 트랜지스터(transparent thin-film transistor, $\mathrm{TTFT}$ )에 $\mathrm{ZnO}$ 를 이용하는 연구가 진행되고 있다. ${ }^{10-12)}$

$\mathrm{ZnO}$ 박막을 형성하기 위한 방법으로 스퍼터링(sputtering) 과 펄스 레이저 증착법(pulsed laser deposition, PLD)과 같은 물리 기상 증착법(physical vapor deposition, PVD) 이 사용되어 왔다. ${ }^{12,13)}$ 하지만, 최근에는 정확한 두께 조 절과 우수한 표면 균일성 등의 장점을 갖는 원자층 증착 법(atomic layer deposition $\mathrm{ALD}$ )을 이용하여 $\mathrm{ZnO}$ 가 증착 되고 있다. ${ }^{14-18)}$ 특히, 박막 트랜지스터(thin-film transistor, TFT)의 활성화 채널층(active channel layer) 형성을 위하 여 저온 박막 공정이 요구되어 $\mathrm{ALD}$ 기술이 더욱 중요 해지고 있다.

$\mathrm{ALD}$ 기술을 이용한 $\mathrm{ZnO}$ 박막 형성에는 $d i$-methylzinc $\left(\mathrm{Zn}\left(\mathrm{CH}_{3}\right)_{2}, \mathrm{DMZ}\right)$ 와 di-ethylzinc $\left(\mathrm{Zn}\left(\mathrm{C}_{2} \mathrm{H}_{5}\right)_{2}, \mathrm{DEZ}\right)$ 와 같 은 $\mathrm{Zn}$ 전구체(precursor)가 사용되고 있다. ${ }^{18-21)}$ 하지만 $\mathrm{Zn}$ 전구체 자체에 대한 계산 연구는 진행되어 왔으나 ${ }^{22-24)}$, 전 구체와 $\mathrm{Si}$ (001) 기판과의 표면 반응에 대한 계산 연구 는 $\operatorname{Ren}^{25}$ 과 Dong 등 ${ }^{26)}$ 의 보고를 제외하고는 거의 진행 된 것이 없다. 그들은 $\mathrm{DEZ}$ 의 초기 표면 반응을 이해하 
기 위해 $\mathrm{Si}(001)$ 표면과의 초기 반응을 연구하였으며, 표 면 반응에 요구되는 에너지 장벽(energy barrier)이 각각 0.47 와 $1.43 \mathrm{eV}$ 로 보고하였다. Ren의 계산에 사용된 $\mathrm{Si}$ 표 면이 화학적으로 반응이 우수한 수산화기(hydroxyl, $-\mathrm{OH}$ ) 로 처리되었기 때문에, Ren의 결과는 수소 $(\mathrm{H})$ 원자로 처 리된 $\mathrm{Si}$ 표면을 사용한 Dong 등의 에너지 장벽보다 매 우 작은 것을 알 수 있다. 하지만, 두 연구에서 사용한 $\mathrm{Si}$ 표면 사이즈가 $2 \times 1$ 으로 작기 때문에 $\mathrm{Zn}$ 전구체의 이 동에 관한 거동은 연구되지 않았으며, 이완되지 않은 구 조를 사용하여 정확한 에너지 장벽이 계산되지 않았다. 본 연구는 밀도 범함수 이론(density functional theory, DFT) 을 이용하여 $4 \times 4$ 크기를 갖는 $\mathrm{Si}(001)$ 표면에서의 $\mathrm{DMZ}$ 와 DEZ의 흡착 거동 및 초기 반응 메커니즘을 비교 고 찰하였다.

\section{2. 계산 방법}

모든 계산은 projector augmented wave (PAW) 포텐셜 과 generalized gradient approximation (GGA)를 포함한 Vienna $a b$-initio simulation package (VASP) 코드로 계산 되었다. ${ }^{27-30)}$ 전자의 바닥 상태를 계산하기 위하여 residual minimization method of direct inversion in the iterative subspace (RMM-DIIS)가 사용되었다. ${ }^{31,32)} \mathrm{Si}$ 원자의 $3 s^{2}$ 와 $3 p^{2}$ 상태, $\mathrm{H}$ 원자의 $1 s^{1}$ 상태, $\mathrm{Zn}$ 원자의 $3 d^{10}$ 와 $4 s^{2}$ 상태, $\mathrm{C}$ 원자의 $2 s^{2}$ 와 $2 p^{2}$ 상태, $\mathrm{O}$ 원자의 상태는 $2 s^{2}$ 와 $2 p^{4}$ 최 외각 파동 함수로 고려되었다. 사용된 cutoff energy는 $500 \mathrm{eV}$ 이고, $k$-points mesh는 진공을 포함한 slab 구조에

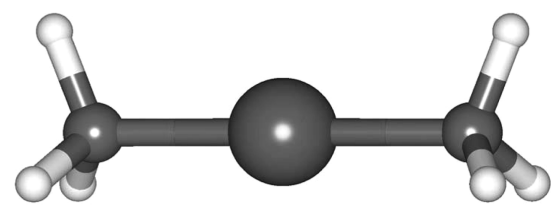

(a)

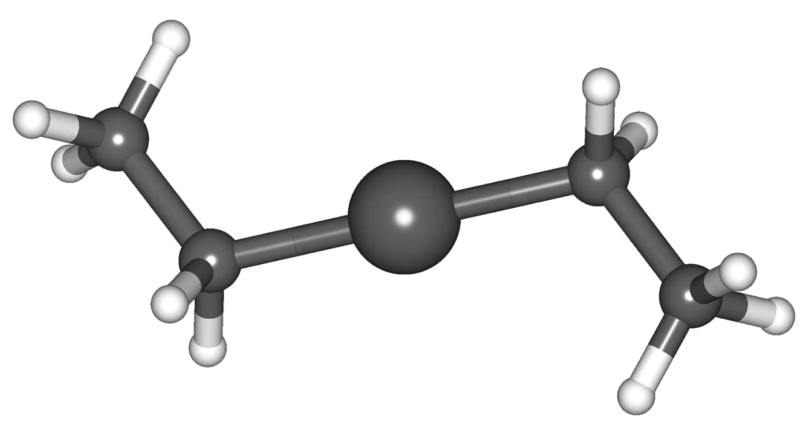

(b)

Fig. 1. Perspective views of (a) DMZ and (b) DEZ molecules. DMZ and DEZ are composed by two methyl's and two ethyl's, respectively. Blue, grey, and white spheres are $\mathrm{Zn}, \mathrm{C}$, and $\mathrm{H}$ atoms.
서 Monk-horst pack을 이용한 $2 \times 2 \times 1$ 크기가 사용되 었다. Gaussian 방법을 사용하였으며, spin-polarization는 사용하지 않았다.

Fig. 1 은 한 개의 $\mathrm{Zn}$ 원자와 메틸기 (methyl, $\left.-\mathrm{CH}_{3}\right)$ 가 두 개 결합한 $\mathrm{DMZ}$ 와 에틸기 (ethyl, $-\mathrm{C}_{2} \mathrm{H}_{5}$ )가 두 개 결합 한 DEZ의 분자 구조를 보여준다. DMZ 혹은 DEZ가 수 산화기 $(-\mathrm{OH})$ 로 처리된 $\mathrm{Si}(001)$ 표면에 흡착될 때 에너 지 관점에서 가장 안정한 자리를 구하였고, 두 전구체가 이동과 반응할 때의 에너지 장벽(energy barrier)을 계산 하였다. 모든 에너지 장벽 계산은 VASP 코드에 포함된 climbing nudged elastic band (CNEB) 도구를 이용하여 수행되었다. ${ }^{33)}$ 또한, 에너지 장벽을 계산할 때 원자들을 이완시켜 응력 변화에 의한 에너지를 최소화하였다.

\section{3. 결과 및 고찰}

Fig. 2는 수산화기 $(-\mathrm{OH})$ 가 처리된 $\mathrm{Si}(001)$ 표면에 흡 착된 $\mathrm{DMZ}$ 와 $\mathrm{DEZ}$ 를 보여준다. 두 전구체의 $\mathrm{Zn}$ 원자가 $-\mathrm{OH}$ 의 $\mathrm{O}$ 원자 위에 위치하는 것이 에너지 관점에서 안 정하였다. 상대적으로 양의 전하를 갖는 $\mathrm{Zn}$ 원자가 $\mathrm{O}$ 원 자의 고립 전자쌍(lone pair electrons)에 의하여 $\mathrm{O}$ 원자 위에 위치하는 것으로 판단된다. $\mathrm{DMZ}$ 의 $\mathrm{Zn}$ 원자와 $\mathrm{O}$ 원자의 거리는 $2.65 \AA$ 이고, $\mathrm{DEZ}$ 의 $\mathrm{Zn}$ 원자와 $\mathrm{O}$ 원자의 거리는 $3.29 \AA$ 이다. 흡착 후 상대적 에너지는 흡착 전보

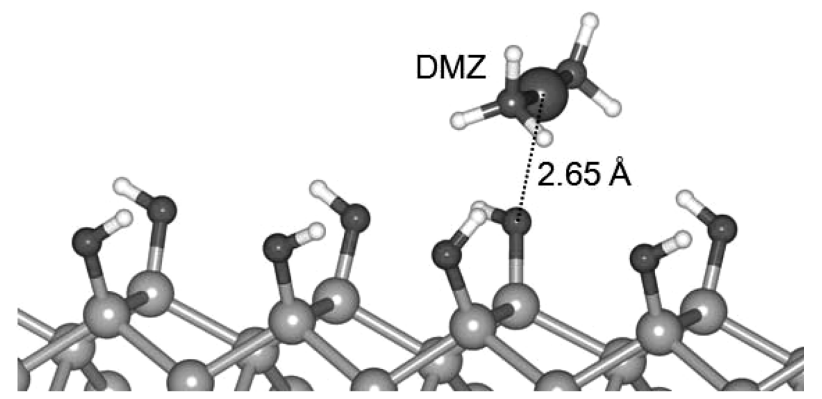

(a)

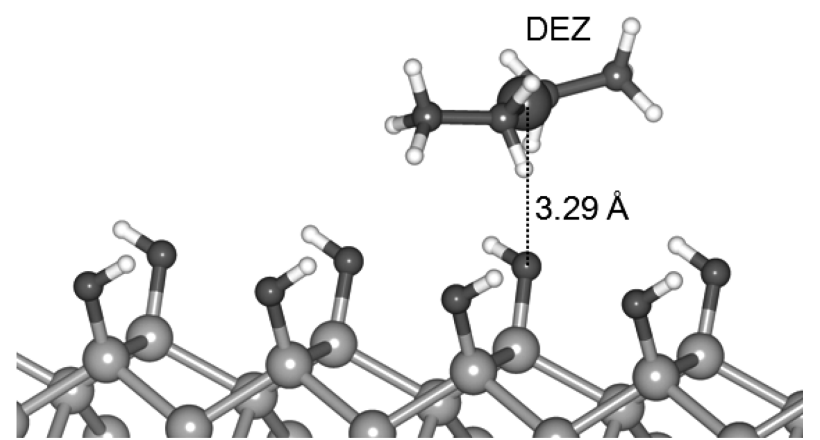

(b)

Fig. 2. Perspective views of (a) DMZ and (b) DEZ adsorption on the fully OH-terminated Si (001) surface. shown along the [100] direction. 


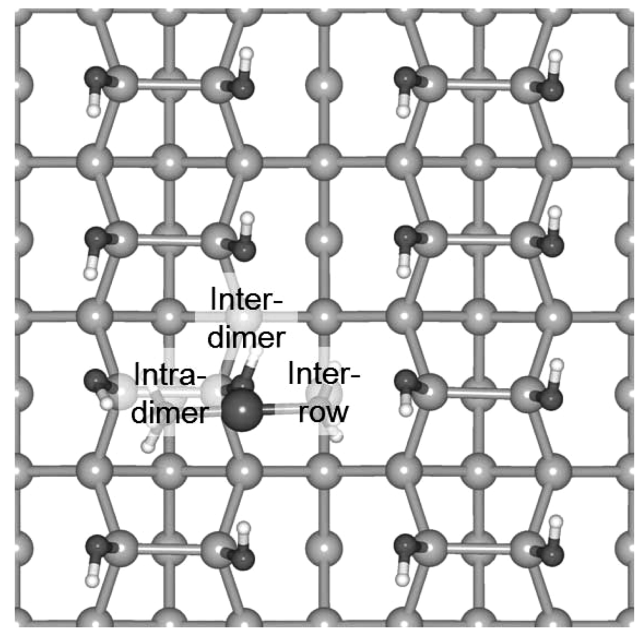

(a)

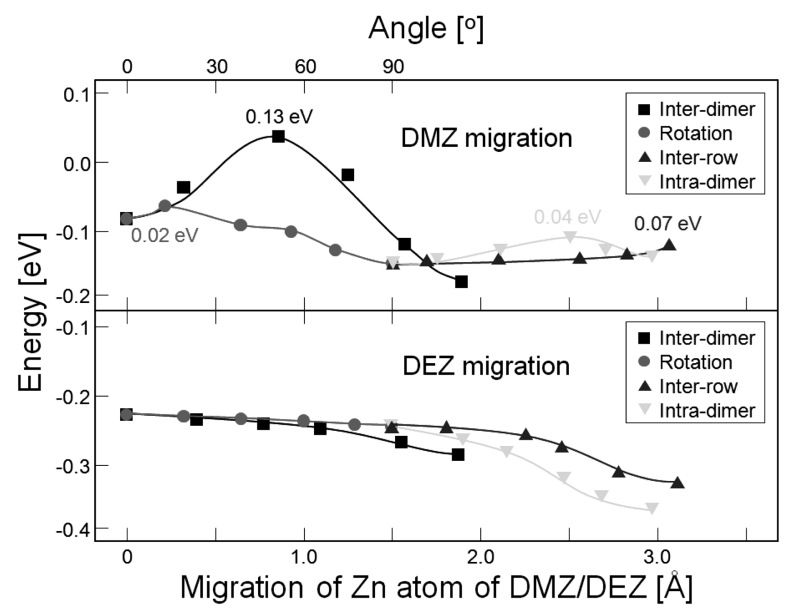

(b)

Fig. 3. Planar views of (a) the DMZ adsorbed on the fully OHterminated Si (001) surface, shown along the [001] direction. (b) Energy barriers for the DMZ and DEZ migration on the surface.

다 각각 -0.09 와 $-0.22 \mathrm{eV}$ 로 감소하였다. 두 전구체가 표면으로부터 영향을 받지 않는 $10 \AA$ 의 거리로 멀리 존 재할 때의 상대적 에너지를 $0 \mathrm{eV}$ 로 기준하였다.

$\mathrm{O}$ 원자 위에 위치한 $\mathrm{DMZ}$ 와 $\mathrm{DEZ}$ 는 주변에 위치한 inter-dimer, intra-dimer, inter-row의 표면 자리로 이동할 수 있다. Fig. 3(a)는 DMZ 주변에 존재하는 세 개의 다른 자 리를 보여준다. $\mathrm{DEZ}$ 의 경우는 $\mathrm{DMZ}$ 와 동일하게 거동하 기 때문에 DMZ의 경우만 표시하였다. DMZ가 inter-dimer 자리로 회전없이 이동할 경우, $0.13 \mathrm{eV}$ 의 에너지 장벽이 요구되었다(Fig. 3(b)). DMZ는 추후 반응을 위해 intradimer와 inter-row 자리로 이동하기 전에 $90^{\circ}$ 회전하고, 요 구되는 에너지 장벽은 $0.02 \mathrm{eV}$ 였다. 회전된 DMZ가 intradimer와 inter-row 자리로 이동할 경우, 요구되는 에너지 장 벽은 각각 0.07 과 $0.04 \mathrm{eV}$ 였다. 즉, 흡착된 $\mathrm{DMZ}$ 는 작은 에너지 장벽에 의하여 표면에서 쉽게 이동 또는 회전하 였다. DEZ는 에너지 장벽없이 회전하거나 이동하였다.

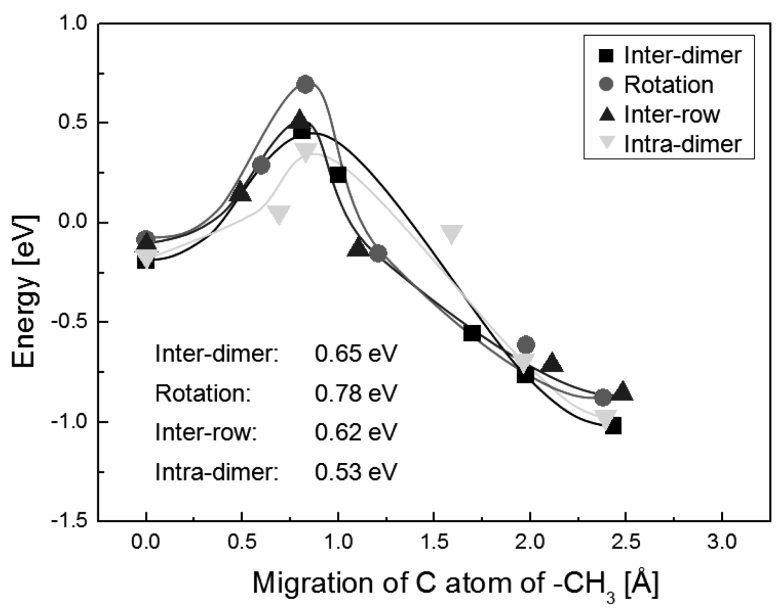

(a)

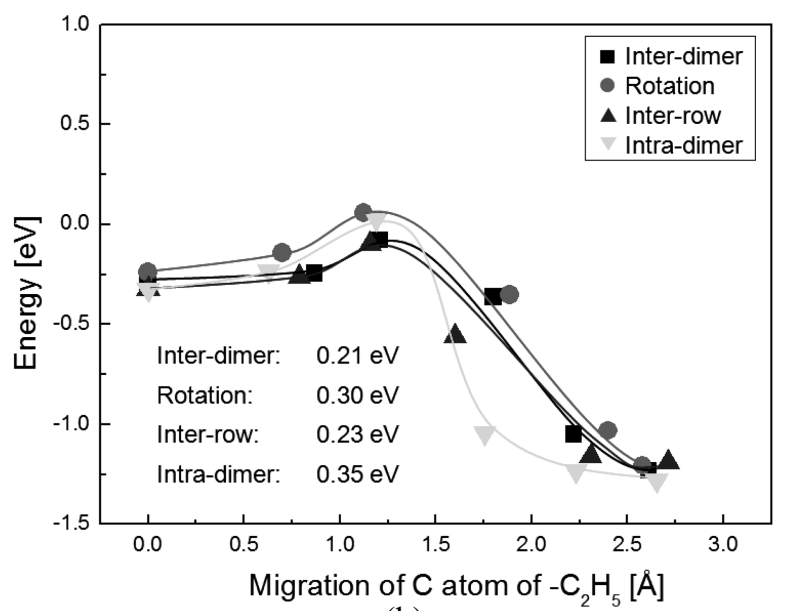

(b)

Fig. 4. Energy barriers for (a) DMZ and (b) DEZ reactions on the fully $\mathrm{OH}$-terminated $\mathrm{Si}(001)$ surface.

회전 또는 기 언급된 세자리로 이동한 $\mathrm{DMZ}$ 와 $\mathrm{DEZ}$ 는 $-\mathrm{OH}$ 와 반응하여 각각 uni-methylzinc $\left(-\mathrm{ZnCH}_{3}, \mathrm{UMZ}\right)$ 와 메탄 $\left(\mathrm{CH}_{4}\right)$, uni-ethylzinc $\left(-\mathrm{ZnC}_{2} \mathrm{H}_{5}, \mathrm{UEZ}\right)$ 와 에탄 $\left(\mathrm{C}_{2} \mathrm{H}_{6}\right)$ 을 생성시킨다. 이 때의 화학 반응식은 다음과 같다.

$$
\begin{aligned}
& -\mathrm{OH}+\mathrm{Zn}\left(\mathrm{CH}_{3}\right)_{3} \rightarrow-\mathrm{O}-\mathrm{ZnCH}_{3}+\mathrm{CH}_{4} \\
& -\mathrm{OH}+\mathrm{Zn}\left(\mathrm{C}_{2} \mathrm{H}_{5}\right)_{2} \rightarrow-\mathrm{O}-\mathrm{ZnC}_{2} \mathrm{H}_{5}+\mathrm{C}_{2} \mathrm{H}_{6}
\end{aligned}
$$

Fig. 4는 각각의 자리에서 $\mathrm{UMZ}$ 와 UEZ의 형성에 요 구되는 에너지 장벽을 보여준다. DMZ의 경우, 회전된 자 리, inter-dimer, inter-row, intra-dimer 자리에서 UMZ와 $\mathrm{CH}_{4}$ 가 형성되기 위한 에너지 장벽은 각각 $0.78,0.65$, $0.62,0.53 \mathrm{eV}$ 이다(Fig. 4(a)). Arrenius 형식의 식을 이용 하여 UMZ가 형성되는 곳을 확률적으로 고려해보면, intradimer 자리에 $\mathrm{UMZ}$ 가 주로 형성된다고 판단된다. $\mathrm{DEZ}$ 의 경우, 회전된 자리, inter-dimer, inter-row, intra-dimer 자 리에서 $\mathrm{UEZ}$ 와 $\mathrm{C}_{2} \mathrm{H}_{6}$ 가 형성되기 위한 에너지 장벽은 각 
각 $0.21,0.30,0.23,0.35 \mathrm{eV}$ 이다(Fig. $4(\mathrm{~b}))$. 이 에너지 장 벽은 $\mathrm{CNEB}$ 도구를 사용하여 원자를 충분히 이완시켰기 때문에 $\operatorname{Ren}^{25}$ 의 결과보다 낮다. UEZ는 에너지 장벽의 차 이가 크지 않아 네 자리에서 비슷한 확률로 형성된다고 판 단된다. 따라서 $\mathrm{DEZ}$ 반응에 요구되는 에너지 장벽의 범 위가 0.21-035 eV로서 DMZ 반응에 요구되는 에너지 장 벽의 범위 $(0.53-0.78 \mathrm{eV})$ 보다 작기 때문에, 저온 $\mathrm{ZnO}$ 박막 을 형성하기 위해서는 반응성 측면에서 DEZ가 더 적합 한 $\mathrm{Zn}$ 전구체라고 판단된다.

\section{4. 결 론}

본 연구는 수산화기 $(-\mathrm{OH})$ 로 처리된 $\mathrm{Si}(001)$ 표면과 $\mathrm{Zn}$ 전구체인 $\mathrm{DMZ}$ 와 $\mathrm{DEZ}$ 의 반응에 관한 것으로, 밀도 범함 수 이론을 이용하였다. DMZ와 DEZ는 표면에 존재하는 $-\mathrm{OH}$ 의 $\mathrm{O}$ 원자 위에 흡착된다. 두 전구체 모두 작은 에 너지 장벽으로 표면에서 쉽게 이동 또는 회전한다. $\mathrm{DMZ}$ 가 반응하여 $\mathrm{UMZ}$ 를 형성하기 위하여 요구되는 에너지 장벽의 범위는 $0.53-0.78 \mathrm{eV}$ 이며, DEZ가 반응하여 $\mathrm{UEZ}$ 를 형성하기 위하여 요구되는 에너지 장벽의 범위가 0.21$0.35 \mathrm{eV}$ 이다. 따라서 $\mathrm{DEZ}$ 의 반응에너지 장벽이 $\mathrm{DMZ}$ 반 응의 경우보다 작기 때문에 $\mathrm{DEZ}$ 가 저온 $\mathrm{ZnO}$ 박막 형성 에 더 적합한 전구체로 판단된다.

\section{감사의 글}

이 논문은 2009년도 정부 (교육과학기술부)의 재원으 로 한국연구재단의 지원을 받아 수행된 기초연구사업임 (No. 2009-0089980).

\section{참 고 문 헌}

1. D. C. Look, Mater. Sci. Eng., B80, 383 (2001).

2. M. H. Huang, S. Mao, H. Feick, H. Yan, Y. Wu, H. Kind, E. Weber, R. Russo and P. Yang, Science, 292, 1897 (2001).

3. H. T. Wang, B. S. Kang, F. Ren, L. C. Tien, P. W. Sadik, D. P. Norton, S. J. Pearton and J. Lim, Appl. Phys. Lett., 86, 243503 (2005).

4. M. Law, L. E. Greeme, J. C. Johnson, R. Saykally and P. Yang, Nat. Mater., 4, 255 (2005).

5. S. J. Pearton, D. P. Norton, K. Ip, Y. W. Heo and T. Steiner, Progr. Mater. Sci., 50, 293 (2005).

6. S. K. Hazra and S. Basu, Solid State Electron., 49, 1158 (2005).

7. S. Muthukumar, C. R. Gorla, N. W. Emanetoglu, S. Liang and Y. Lu, J. Cryst. Growth, 225, 197 (2001).

8. V. Assuncao, E. Fortunato, A. Marques, H. Aguas, I.
Ferreira, M. E. V. Costa and R, Martins, Thin Solid Films, 427, 401 (2003).

9. S. Jagar, B. Szyszka, J. Szczyrbowski and G. Bauer, Surf. Coating. Tech., 98, 1304 (1998).

10. N. L. Hung, H. Kim and D. Kim, Kor. J. Mater. Res., 20, 235 (2010) (in Korean).

11. S. Park, H. Jung, E. Ahn, L. H. Nguyen, Y. Kang, H. Kim and D. Kim, Kor. J. Mater. Res., 18, 655 (2008) (in Korean).

12. S. Masuda, K. Kitamura, Y. Okumura and S. Miyatake, J. Appl. Phys., 93, 1624 (2003).

13. P. F. Carcia, R. S. McLean, M. H. Reilly and G. Nunes Jr., Appl. Phys. Lett., 82, 1117 (2003).

14. E. Fortunato, P. Barguinha, A. Pimentel, A. Gonçalves, A. Marques, L. Pereira and R. Martins, Adv. Mater., 17, 590 (2005).

15. A. N. Banerjee, C. K. Ghosh, K. K. Chattopadhway, H. Minoura, A. Sarkar, A. Akiba, A. Kamiya and T. Endo, Thin Solid Films, 496, 112 (2006).

16. A. Yamada, B. Sang and M. Konagai, Appl. Surf. Sci., 112, 216 (1997).

17. V. Lujala, J. Skarp, M. Tammenmaa and T. Suntola, Appl. Surf. Sci., 82-83, 34 (1994).

18. E. Yousfi, J. Fouache and D. Lincot, Appl. Surf. Sci., 153, 223 (2000).

19. A. W. Ott and R. P. H. Chang, Mater, Chem, Phys., 58, 132 (1999).

20. S. K. Kim, C. S. Hwang, S. -H. Ko Park and S. J. Yun, Thin Solid Films, 478, 103 (2005).

21. S. J. Lim, J. W. Elam and M. J. Pellin, Thin Solid Films, 516, 6158 (2008).

22. D. M. King, X. Liang, P. Li and A. W. Weimer, Thin Solid Films, 516, 8517 (2008).

23. R. Triboulet and J. Perrière, Progr. Cryst. Growth Char. Mater., 47, 65 (2003).

24. M. F. Guest, I. H. Hillier and V. R. Saunders, J. Organomet. Chem., 44, 59 (1972).

25. N. Maung, J. Mol. Struct., 434, 255 (1998).

26. Y. S. Kim, Y. S. Won, H. Hagelin-Weaver, N. Omenetto and T. Anderson, J. Phys. Chem. A, 112, 4246 (2008).

27. J. Ren, Appl. Surf. Sci. 255, 5742 (2009).

28. L. Dong, Q.-Q. Sun, H.-W. Guo, H. Liu, S.-J. Ding and D. W. Zhang, Thin Solid Films, 517, 4355 (2009).

29. G. Kresse and J. Hafner, Phys. Rev. B, 47, 558 (1993); ibid 49, 14251 (1994).

30. G. Kresse and J. Furthmüller, Comput. Mat. Sci., 6, 15 (1996).

31. G. Kresse and J. Furthmüller, Phys. Rev. B, 54, 11169 (1996).

32. G. Kresse and D. Joubert, Phys. Rev. B, 59, 1758 (1999).

33. D. M. Wood and A. Zunger, J. Phys. A, 18, 1343 (1985).

34. P. Pulay, Chem. Phys. Lett., 73, 393 (1980).

35. D. Sheppard and R. Terrell, G. Henkelman, J. Chem. Phys., 128, 134106 (2008). 